\title{
ASSOCIATION OF FRAILTY WITH VITAMIN D IN ELDERLY WOMEN
}

\author{
Justina Kilaitė ${ }^{*}$, Asta Mastavičiūtė², Marija Tamulaitienėe, ${ }^{2,3}$, Vidmantas Alekna1 \\ ${ }^{1}$ Faculty of Medicine, Vilnius University, Lithuania; ${ }^{2}$ Department of Rehabilitation, Physical and Sports Medicine, Faculty of \\ Medicine, Vilnius University, Lithuania; ${ }^{3}$ National Osteoporosis Center, Vilnius, Lithuania
}

\section{INTRODUCTION}

Frailty is geriatric syndrome which leads to vulnerability and decreased physiological reserves [1]. Some studies showed that low levels of vitamin $D$ are associated with frailty [2]. K. E. Ensrud et al. stated that components of frailty such as weakness and slowness are potential outcomes of vitamin D deficiency [3]. However, links between frailty and vitamin $\mathrm{D}$ deficiency are controversial.

\section{OBJECTIVE}

The aim of this study was to investigate association between frailty and vitamin $D$ in community dwelling elderly women.

\section{MATERIALS AND METHODS}

A retrospective cross - sectional study was performed in National

Osteoporosis Centre based in Vilnius, Lithuania. Inclusion criteria were: female, age 60 years and older, no current use of vitamin $D$ supplements. Frailty status was defined using Fried's criteria: 1. weakness, measured by handgrip strength; participants in the lowest quintile were included; 2. low walking speed, defined by 4 meter walking test performance; criteria was met for women in the highest quintile; 3 . low physical activity, measured using Physical Activity Scale for the Elderly (PASE); subjects in the lowest quintile met the criteria; 4. weight loss, defined as unintentional loss of at least 5 kilograms during last year; 5 . exhaustion, which is measured using 10-item Center for Epidemiological Studies Depression Scale (CES-D 10); criteria was met for participants scoring $\geq 10$ points [4]. Women were classified as robust, pre-frail and frail if they scored $0,1-2, \geq 3$ out of 5 points, respectively. Vitamin $\mathrm{D}(25(\mathrm{OH}) \mathrm{D})$ concentration in serum was measured with Cobas E411 (Roche Diagnostic, Germany). Statistical analysis was carried out with SPSS 20.0 program for

Windows. Normality of the data was evaluated with Shapiro-Wilk test. Group differences were examined using Kruskal-Wallis test. Association between frailty and vitamin $D$ was determined with multinomial logistic regression. P-value of $<0.05$ was considered as statistically significant.

\section{RESULTS}

The study was performed on 161 women: $103(64 \%)$ robust, 30 (18.6\%) pre-frail and $28(17.4 \%)$ frail. Anthropometrical and biochemical characteristics of study participants are shown in Table 1.

Table 1. Anthropometrical and biochemical characteristics
of frailty phenotype groups
\begin{tabular}{|l|c|c|c|c|}
\hline Characteristic & $\begin{array}{c}\text { Robust } \\
(\mathrm{n}=103)\end{array}$ & $\begin{array}{c}\text { Pre-frail } \\
(\mathrm{n}=30)\end{array}$ & $\begin{array}{c}\text { Frail } \\
(\mathrm{n}=28)\end{array}$ & $\mathrm{p}$ \\
\hline Age (yrs) & $69.4 \pm 6.2$ & $70.8 \pm 7.9$ & $75.8 \pm 5.9$ & $<0.001$ \\
\hline Height $(\mathrm{cm})$ & $160.5 \pm 6.5$ & $157.2 \pm 6.6$ & $157.4 \pm 5.1$ & 0.02 \\
\hline Weight $(\mathrm{kg})$ & $71.6 \pm 12.8$ & $71 \pm 12.4$ & $75.1 \pm 14.9$ & 0.48 \\
\hline BMI (kg/m²) & $27.9 \pm 5.9$ & $28.7 \pm 4.6$ & $30.2 \pm 5.3$ & 0.12 \\
\hline $25(\mathrm{OH}) \mathrm{D}(\mathrm{ng} / \mathrm{ml})$ & $17.6 \pm 8.2$ & $16.2 \pm 6.4$ & $13.3 \pm 6.2$ & 0.03 \\
\hline BMI - body mass index, $25(\mathrm{OH}) \mathrm{D}-25$ hydroxyvitamin D \\
\end{tabular}

Frailty phenotype groups statistically significantly differed in age $(p<0.001)$, height $(p=0.02)$ and vitamin $D$ concentration $(p=0.03)$. Frail women were the oldest (75.8 $5.9 \mathrm{yrs}$, $p<0.001)$, the shortest $(157.45 .1 \mathrm{~cm}$, $\mathrm{p}=0.02$ ) and had the lowest vitamin $\mathrm{D}$ concentration $(13.36 .2 \mathrm{ng} / \mathrm{ml}$, $\mathrm{p}=0.03$ ). However, weight and body mass index were not statistically significant between frailty phenotype groups $(p=0.48$ and $p=0.12$, respectively). Associations between frailty and changes of vitamin $D$ levels are summarized in Table 2.

Unadjusted analysis represented in model 1 showed that in frailty versus robust group high levels of vitamin D were statistically significantly associated with probability of being less frail (OR: $0.91,95 \% \mathrm{Cl}: 0.85-$ $0.97, p=0.009$ ). In other words, robust women were more likely to

Table 2. Association between frailty and vitamin D in
different frailty statuses
\begin{tabular}{|l|c|c|c|}
\hline \multirow{2}{*}{ Variables } & \multicolumn{2}{|l}{$\begin{array}{l}\text { Probability of vitamin D decrease, odds ratio } \\
(95 \% \text { confidence interval })\end{array}$} \\
\cline { 2 - 5 } & $\begin{array}{c}\text { Pre-frailty vs } \\
\text { Robust }\end{array}$ & $\begin{array}{c}\text { Frailty vs } \\
\text { Robust }\end{array}$ & $\begin{array}{c}\text { Frailty vs } \\
\text { Pre-frailty }\end{array}$ \\
\hline Model 1 & $0.98(0.92-1.03)$ & $0.91(0.85-0.98)^{*}$ & $0.93(0.86-1.01)$ \\
\hline Model 2 & $0.98(0.93-1.04)$ & $0.96(0.89-1.03)$ & $0.97(0.89-1.06)$ \\
\hline Model 3 & $0.98(0.92-1.04)$ & $0.96(0.89-1.03)$ & $0.97(0.89-1.06)$ \\
\hline Model 4 & $0.98(0.93-1.04)$ & $0.95(0.88-1.03)$ & $0.97(0.89-1.06)$ \\
\hline Model 5 & $0.98(0.92-1.04)$ & $0.95(0.88-1.03)$ & $0.97(0.89-1.06)$ \\
\hline${ }^{*}-p<0.05$ & & &
\end{tabular}

have higher vitamin $D$ concentration than frail women. After adjusting for the age (model 2), association between frailty and vitamin $D$ in the same group (frailty versus robust) was not statistically significant $(p=0.26)$. That is why, age was also added to models 3,4 and 5 which represent adjustment for: height, weight and $\mathrm{BMI}$, respectively. Associations between frailty and vitamin $D$ concentration were not statistically significant in all of these models. Furthermore, no statistically significant relationships before and after adjustments were observed in other multinomial logistic regression groups: pre-frailty versus robust and pre-frailty versus frailty groups.

\section{CONCLUSIONS}

In elderly women unadjusted high levels of vitamin $D$ are associated with being robust. Age adjusted high vitamin $D$ concentration is not related to being robust. Age is the independent risk factor of frailty. No associations between vitamin $\mathrm{D}$ and pre-frailty status were found.

No conflicts of interest.

\section{REFERENCES}

1. Vogt S, et al. Prev Med. 2015; 73:40-6. 2. Hirani V, et al. J Gerontol A Biol Sci Med Sci. 2013; 68(9):1112-21.

3. Ensrud KE, et al. J Clin Endocrinol Metab. 2010; 95(12):5266-73.

4. Alvarez-Ríos Al, et al. Exp Gerontol. 2015; 69:79-84. 